\title{
CONTRIBUIÇÕES DOS SISTEMAS DE INFORMAÇÃO AMBIENTAL (SIAS) NO PROCESSO DE LICENCIAMENTO AMBIENTAL: O CASO DO PROMABEN, BELÉM - PA
}

\author{
CONTRIBUTIONS OF ENVIRONMENTAL INFORMATION SYSTEMS (SIA) IN THE PROCESS OF \\ ENVIRONMENTAL LICENSING: THE PROMABEN CASE, BELÉM - PA
}

\author{
Antônio Carlos Ribeiro Araújo Júnior ${ }^{1}$ \\ ${ }^{1}$ Universidade Federal de Roraima (UFRR), Boa Vista, RR, Brasil

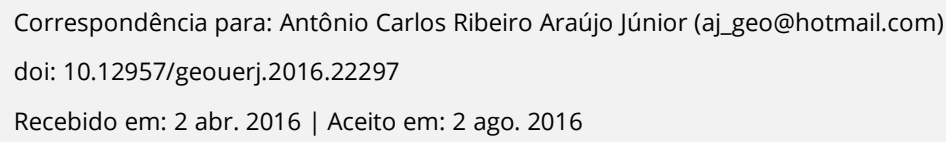

\section{RESUMO}

Os Sistemas de Informação Ambiental (SIAs) constituem importantes ferramentas nas tomadas de decisão em processos de intervenção ambiental que afeta direta e/ou indiretamente a sociedade, por não somente esclarecer, mas por apresentar informações suficientes para reflexão de uma práxis concreta. No entanto, mesmo após a promulgação da Lei do Direito à Informação (Lei 10.650, de 16 de abril de 2003) muitas informações ainda são omitidas ou se criam dificuldades para seu acesso, podendo comprometer o entendimento da realidade em seu todo (o holos) por parte principalmente da sociedade civil. Assim, tem-se como objetivo entender as contribuições dos SIAs em processos de tomada de decisão. Para tanto foi selecionado o caso do licenciamento ambiental do Programa de Macrodrenagem da Bacia Hidrográfica da Estrada Nova (PROMABEN) e suas nuances de implantação sobre a área desta bacia hidrográfica. A metodologia está aportada no viés sistêmico, levantamentos bibliográficos e documentais e trabalhos de campo para verificar por meio de observação sistemática se o andamento da obra acompanha as diretrizes legais do programa.

Palavras-chave: Informação, participação, sociedade.

\section{ABSTRACT}

The Environmental Information Systems (SIAs) are important tools in decision making in environmental of intervention processes that affect directly and / or indirectly to society, not only clarify, but provide enough information for reflection of a concrete praxis. However, even after the enactment of the Right to Information Act (Law 10,650, of April 16, 2003) a lot of information is still omitted or create difficulties for access, which could compromise the understanding of reality in its whole (holos) mainly by civil society. Thus, it has been aimed at understanding the contributions of SIAs in decisionmaking processes. Therefore was selected case of environmental licensing Macrodrainage Program of the Hydrographic Basin of New Road (PROMABEN) and its implementation nuances of the area of this watershed. The methodology is grounded in systemic bias, bibliographic and documentary surveys and field work to verify through systematic observation is the progress of the work follows the legal guidelines of the program.

Keywords: Information, participation, society.

\section{INTRODUÇÃO}

A lei no 10.650, de 16 de abril de 2003, que dispõe sobre o acesso público aos dados e informações existentes nos órgãos e entidades integrantes do Sistema Nacional do Meio Ambiente (SISNAMA) dispõe em seu artigo $1^{0}$ sobre o acesso público aos dados e informações ambientais existentes nos 
órgãos e entidades integrantes do SISNAMA, instituído pela Lei no 6.938, de 31 de agosto de 1981. Além disso, em seu artigo $2^{0}$ diz que documentos que tratem de matéria ambiental devem ser disponibilizados pelos órgãos que delas tratem.

Existe de fato uma lei que trata da disponibilização de informações ambientais de órgãos públicos e privados para a sociedade, mas por vezes ainda se percebe a tomada de decisões sendo posta a cabo unicamente pelo poder público, e a população ou a sociedade civil é apenas comunicada e não informada.

Para tanto, acredita-se que a implantação de um Sistema de Informação Ambiental (SIA) teria sido de fundamental importância para a consolidação de fato e de direito dos processos de intervenção estrutural e não estrutural na Bacia Hidrográfica da Estrada Nova (BHEN) - figura 1, bem como em um processo de licenciamento ambiental mais transparente para a sociedade civil.

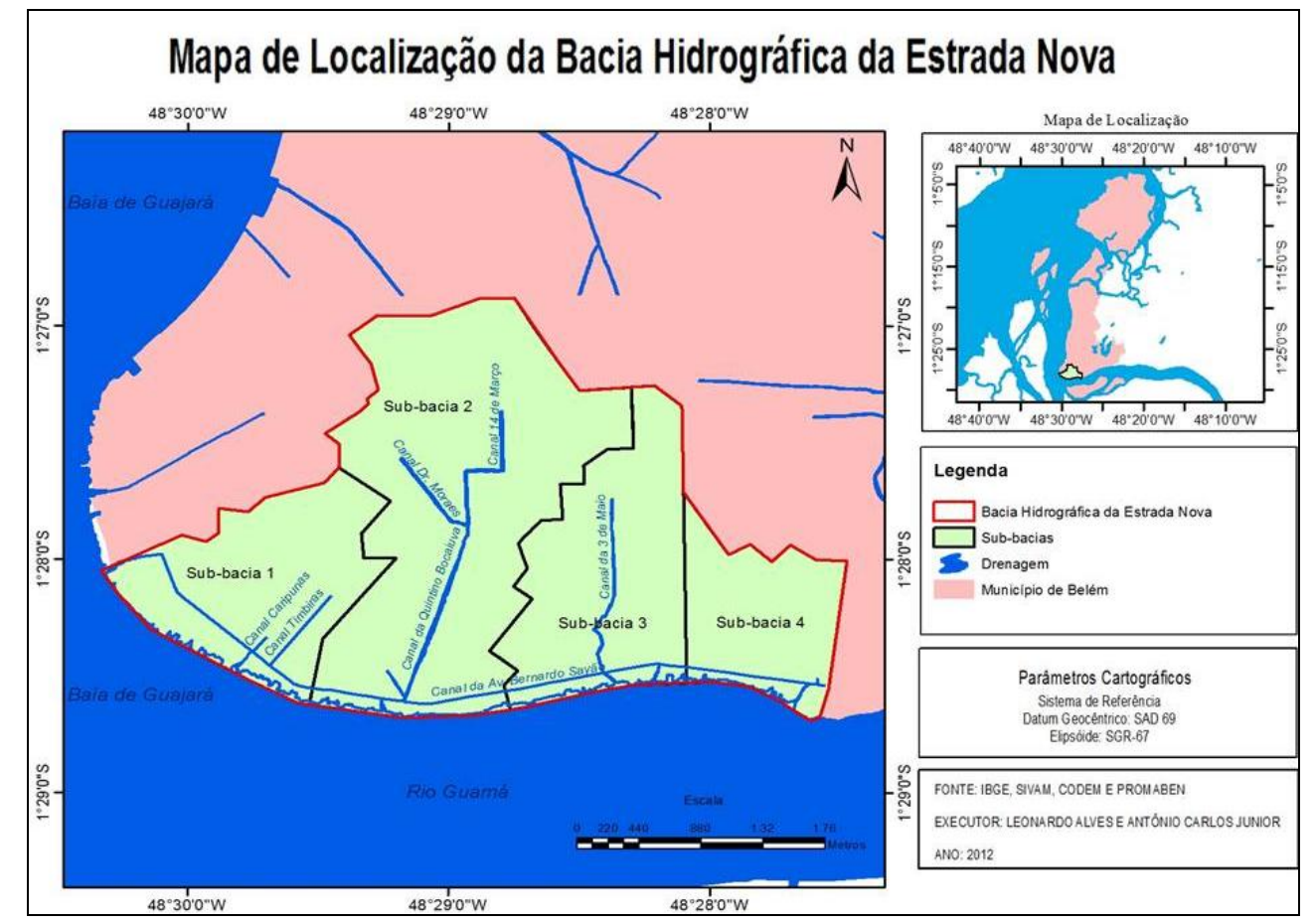

Figura 1. Mapa de localização da Bacia Hidrográfica da Estrada Nova (BHEN) em Belém (PA). Fonte: o autor e Leonardo Alves. 
Assim, tendo como objetivo entender as contribuições dos Sistemas de Informação Ambiental (SIAs) foi selecionado o caso do licenciamento ambiental (LA) do Programa de Macrodrenagem da Bacia Hidrográfica da Estrada Nova (PROMABEN) e suas nuances de implantação sobre a área desta bacia hidrográfica.

Como metodologia foi adotado o viés sistêmico, levantamentos bibliográficos e documentais (Estudo de Impacto Ambiental - EIA e Relatório de Impacto Ambiental - RIMA do PROMABEN) e trabalhos de campo para verificar por meio de observação sistemática se o andamento da obra acompanha as diretrizes legais do programa.

\section{Sistemas de Informação Ambiental (SIAs): algumas considerações}

A discussão sobre como e quando a informação ambiental é cedida e repassada acompanha os movimentos ambientais mundiais de mobilização para discutir questões referentes ao meio ambiente e recursos naturais, os quais estão diretamente ligados a sadia qualidade de vida das presentes e futuras gerações.

Segundo Persegona (2013) um dos resultados esperados da lei 10.650/2003 é a melhoria do Sistema Nacional de Informações sobre Meio Ambiente (SINIMA), criado pela Lei ํㅜ․ 6.938/1981, que dispõe sobre a Política Nacional de Meio Ambiente. O SINIMA apresenta dois pontos focais, (i) sistematização de informações ambientais e (ii) compartilhamento de recursos informacionais referentes ao meio ambiente.

Congregar informações não deve somente considerar o aspecto técnico, uma vez que o acesso a informação para todos os povos do planeta, não ocorre de forma igualitária, devido desigual acesso a tecnologia de informação necessária para processamento e difusão da informação. 
Sistemas de Informação Ambiental (SIAs) seriam bem mais úteis se considerado o aspecto técnico como importante, mas não como fundamental, pois se coaduna com Piper et al. (2003 apud BARROS; PAIVA , 2010), os quais sugerem que SIAs "podem vir a ser ferramentas úteis em processos de articulação, desde que sejam projetados de maneira a envolver as pessoas”.

Quando se fala em difusão de informação não se pode pensar unicamente em hardwares e softwares, posto que a mesma informação não é recebida da mesma forma por esquimós nos desertos gelados ou por beduínos nos desertos quentes.

A assertiva de Davenport (2002) é salutar neste aspecto, pois expõe uma fragilidade no concernente a recepção e difusão da informação, a qual esta ligada a questão dos "usuários finais", os quais não podem ser negligenciados quanto as suas características culturais, as quais sem dúvida diferenciam a maneira de receber a informação a aplicá-la sobre a realidade.

Não se pode apenas criar bancos de dados analógicos e/ou digitais e achar que o mais perfeito SIA foi criado, isto seria desconsiderar o todo (holos) que permeia as relações sociedade-sociedade, naturezanatureza e sociedade-natureza, relações estas que se interconectam e algumas vezes se complementam (figura 2).

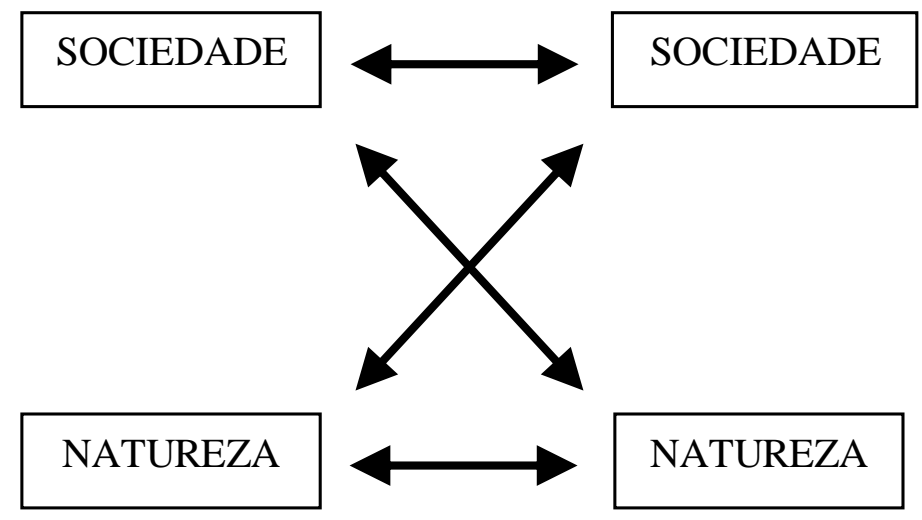

Figura 2. Esquema representando as relações entre sociedade e natureza. Fonte: o autor. 
Deve-se ter clareza que o ambiente informacional, seja ele digital e/ou analógico, é ferramenta para o entendimento das relações que se processam entre natureza e sociedade, em uma profunda análise da aplicação das informações que visem uma práxis transformadora para a compreensão das complexas relações entre estes elementos e assim o fator principal passaria a ser considerado, as pessoas.

Tavares; Freire (2003) dizem que a Informação Ambiental (IA) é um tipo de informação científica e tecnológica a qual tem papel fundamental na superação da crise ambiental vivenciada hoje, contribuindo para a preservação de ambientes naturais e daqueles construídos pelo homem. No entanto, advertem para o descompasso latente entre informação e realidade de aplicação desta informação.

No Brasil, este descompasso é marcante devido ainda não se atribuir a real importância da informação ambiental nos processos decisórios, muito por conta de prioridades “mais urgentes”, como alimentação, saúde, moradia, etc, as quais tomam a frente na hora do debate.

Não se afirma com isso que a discussão e implementação de políticas públicas voltadas para a resolução e/ou mitigação de problemáticas ambientais deva ser deixada de lado por países com situação econômica e social semelhante ao caso brasileiro, mas que no atual momento estas discussões ainda não atingiram seu ápice, talvez por questões políticas, talvez por questões midiáticas.

A informação ambiental contribui para a mudança de condutas e comportamentos, tendo papel fundamental na preservação ambiental, como subsídio para a ação no mundo, contribuindo para a diminuição de incertezas diante do meio ambiente (FREIRE; ARAÚJO, 1999 apud TAVARES; FREIRE, 2003), quer seja natural ou construído pelo homem, pois "para além das necessidades do sistema produtivo, todos temos direito à informação que possa diminuir nossa incerteza diante do meio ambiente, uma informação que subsidie nossa ação no mundo." 
Segundo Caribé (1992) a informação ambiental tem um importante papel de informar os indivíduos sobre os problemas e soluções viáveis sobre a questão ambiental, além de controlar e armazenar a documentação pertinente produzida sobre os assuntos ligados ao meio ambiente, além disso é importante destacar que

A característica principal da informação ambiental, segundo vários autores (FREEMAN, SOMERVILLE, DAVE et al.), é a inter e multidisciplinaridade. A área leva em consideração conceitos científicos, sociais, religiosos e filosóficos, inclui valores políticos e econômicos e discute conceitos das ciências físicas e biológicas. Os assuntos de meio ambiente estão ligados à área científica, médica e de engenharia, tais como Geologia, Geografia, Química, Biologia, Hidrologia, Engenharia Química, Engenharia Ambiental, Engenharia Sanitária, Pesquisa Operacional e outras. Envolvem também as ciências sociais com aspectos econômicos, política econômica, gerenciamento e administração, política governamental e implicações sociais. Para se desenvolver qualquer estudo sistemático na área, são necessários parâmetros e conceitos pertencentes a várias ramificações da ciência e tecnologia (CARIBÉ, 1992, p. 41).

Estas facetas disciplinares podem conduzir a estudos bem efetivos no concernente a levantamentos, armazenamento, processamento e divulgação das informações para a sociedade civil, bem como potencializar processos decisórios mais coerentes com a realidade que cada problema se apresenta.

Mesmo se tratando de aspectos introdutórios, o destaque dado as IAs e a constituição de SIAs ocorre pelo fato se serem instrumental relevante para consolidação de diretrizes legais instituídas, como o SINIMA e subsidiarem a tomada decisões mais condizentes com realidades adversas, pois mesmo tendo posse da informação que um determinado fenômeno vai acontecer, este poderá se processar de diferentes maneiras no tempo e no espaço.

Na mesma medida, as Ias podem ser utilizadas para consolidação mais efetiva de outros instrumentais legais, como os processos de Licenciamento Ambiental (LA) sobre obras públicas que impactem (positiva ou negativamente) o meio ambiente, uma vez que antes do processo de LA, todos os interessados e impactados por quaisquer que sejam as obras devem ser chamados a público para 
tomarem conhecimento do que será implantado, sendo ainda garantido o direito de obter qualquer informação referente aos aspectos ambientais das obras. Isto é de diretito, mas por vezes não é de fato. A importância dos SIAs faz sentido quando se pensa porque determinadas informações podem ser cedidas e outras não? Será que isso é correto? Como isto pode afetar o meio ambiente? De que forma pode-se lidar com isso? Tais perguntas são relevantes e a apresentação do processo de LA do Programa de Macrodrenagem da Bacia Hidrográfica da Estrada Nova (PROMABEN) pode ajudar a melhor compreender a importância de um SIA no LA

\section{Licenciamento Ambiental (LA) do Programa de Macrodrenagem da Bacia Hidrográfica da Estrada Nova (PROMABEN)}

O anexo 1 da Resolução CONAMA nº 237, de 19 de dezembro de 1997 que dispõe sobre as atividades ou empreendimentos sujeitos ao LA, sendo o PROMABEN enquadrado na categoria obras civis, as quais seriam (i) rodovias, ferrovias, hidrovias metropolitanas; (ii) barragens e diques; (iii) canais para drenagem, (iv) retificação de curso de água, (v) abertura de barras, embocaduras e canais, (vi) transposição de bacias hidrográficas e (vii) outras obras de arte, é ferramenta legal componente do processo licitatório a empreendimentos que possam vir a comprometer o equilíbrio ambiental.

Além desta diretriz o processo de licenciamento segue rigidamente os protocolos para obtenção das licenças necessárias a implantação do Programa de Macrodrenagem da Bacia Hidrográfica da Estrada Nova (PROMABEN), quais sejam, a Licença Prévia (LP), Licença de Instalação (LI) e Licença de Operação (LO), sendo estas concedidas pelo órgão ambiental competente, neste caso a Secretaria Municipal de Meio Ambiente (SEMMA) de Belém.

Na resolução CONAMA 237/1997, art. 1º, inciso I, entende-se por Licenciamento Ambiental (LA) o procedimento administrativo pelo qual o órgão ambiental competente licencia a localização, instalação, ampliação e a operação de empreendimentos e atividades utilizadoras de recursos ambientais, consideradas efetiva ou potencialmente poluidoras ou daquelas que, sob qualquer forma, possam causar 
degradação ambiental, considerando as disposições legais e regulamentares e as normas técnicas aplicáveis.

Segundo o art. $6^{\circ}$, compete ao órgão ambiental municipal, ouvido os órgãos competentes da União, dos Estados e do Distrito Federal, quando couber, o LA de empreendimentos e atividades de impacto ambiental local e daquelas que lhe forem delegadas pelo Estado por instrumento legal ou convênio.

Araújo Júnior (2013) diz que a Bacia Hidrográfica da Estrada Nova (BHEN) teve no ano de 2007 seu processo de LA avaliado e aprovado pela Prefeitura Municipal de Belém (PMB) para implantação do PROMABEN, assim empreendeu em seu trabalho a verificação dos objetivos previstos para alcance do seu Estudo de Impacto Ambiental (EIA), bem como no seu Relatório de Impacto Ambiental (RIMA). No ano de 2006, na audiência sobre a "Urbanização da bacia da Estrada Nova e Orla do rio Guamá" foi apresentada uma delimitação da BHEN com algumas possíveis intervenções a serem processadas dentre elas revestimento asfáltico, revestimento em blockret, galerias pluviais, pontes de concreto, passarelas, etc.

Com estas intervenções - e outras mais - o PROMABEN tem por objetivo a promoção da qualidade de vida da população do Município de Belém através da recuperação socioambiental e da valorização do meio ambiente urbano (PMB, 2007a; 2007c), com enfoque à área de influência direta da porção sul da cidade de Belém, abrangendo a BHEN.

A implantação do Programa esta a cargo da Unidade Coordenadora do Programa - UCP, a qual é responsável pela execução da totalidade das ações do Programa, tanto na fase preparatória como na execução, incluindo as ações relativas à implantação do Projeto da Orla de Belém. A UCP é unidade orçamentária com autonomia operacional de forma a proporcionar uma maior agilidade para a implantação do Programa (PMB, 2007c). 
Para a perfeita implantação do Programa de Gestão Ambiental a UCP conta com as estruturas dos órgãos participantes para levar adiante a missão de execução do PROMABEN, estes são a Secretaria Municipal de Saúde (SESMA), Secretaria Municipal de Meio Ambiente (SEMMA), Secretaria Municipal de Habitação (SEHAB), Secretaria Municipal de Urbanismo (SEURB), Serviço Autônomo de Água e Esgoto (SAAEB) - Agência Reguladora, Companhia de Saneamento do Pará (COSANPA), Rede CELPA S/A, Secretaria de Finanças (SEFIN) e Companhia de Desenvolvimento da Área Metropolitana de Belém (CODEM), o qual é complementado pelo Plano de Fortalecimento Institucional, o qual busca dar caráter integrativo para informações dos diferentes órgãos participantes.

Como um todo, os planos e programas componentes do PROMABEN são:

- $\quad$ Plano de Gestão Ambiental e Social do Programa;

- $\quad$ Plano Ambiental da Construção;

- $\quad$ Plano de Fortalecimento Institucional

- $\quad$ Programa de Educação Ambiental

- $\quad$ Programa de Comunicação Social

- $\quad$ Programa de Participação Comunitária

Composto por este aparato de Planos Programas, o EIA tem como princípios fundamentais a busca de alternativas para promover o desenvolvimento sustentado através da reordenação urbana, tomando a referência da BHEN como unidade de planejamento e de soluções integradas para os diversos subsistemas de infraestrutura e serviços urbanos intervenientes com a ocupação do solo (PMB, $2007 \mathrm{c})$.

Araújo Júnior (2013) aponta que mesmo com diretrizes de planejamento voltadas para um desenvolvimento sustentável, verifica-se que o mencionar de elementos físicos como geologia, geomorfologia, clima, vegetação, solo e hidrografia não se fazem suficientes para um entendimento 
holístico do espaço belenense produzido e em produção, sendo necessária uma caracterização mais detalhada para qualquer tipo de intervenção (estrutural e não estrutural).

O sítio de Belém pode ser entendido, segundo o IDESP (1990) como um sistema onde as ações do homem-sociedade provocaram/provocam no processo de desenvolvimento urbano sucessivas transformações no seu sítio, influindo na sua topografia, tipo do solo, recursos hídricos, cobertura vegetal, bem como nas condições microclimáticas.

No entanto, a concepção setorizada das obras de recuperação das baixadas resolve/resolveu situações particulares agravando as condições das vizinhanças, isto porque a elevação das cotas das vias e terrenos isoladamente passa a drenar a água às porções inferiores, inclusive retendo ou dificultando seu escoamento, como é o caso da Av. Bernardo Sayão, potencializando áreas de alagamento e inundação em razão também da penetração das águas do rio Guamá.

O RIMA do PROMABEN retrata de forma pormenorizada elementos sociais e ambientais já destacados no EIA, frisando que as análises tanto do EIA quanto do RIMA, são documentais, uma vez que de 2007 a 2012 (5 anos) somente 1,5 km do PROMABEN foram construídos em termos de corredor viário reestruturado, com vias largas, pistas duplas e passeios públicos amplos (figura 3).

No concernente aos cursos d'água, Araújo Júnior (2013) mostra que o processo de intervenção ainda é inicial, podendo-se perceber forte tendência ao secamento do canal da Bernardo Sayão e demais canais, assim como implantação de micro-drenagem tubular e aterramento dos demais canais (figura 4), evidenciando aspectos latentes de um planejamento urbano, e incipientes de um planejamento ambiental. 


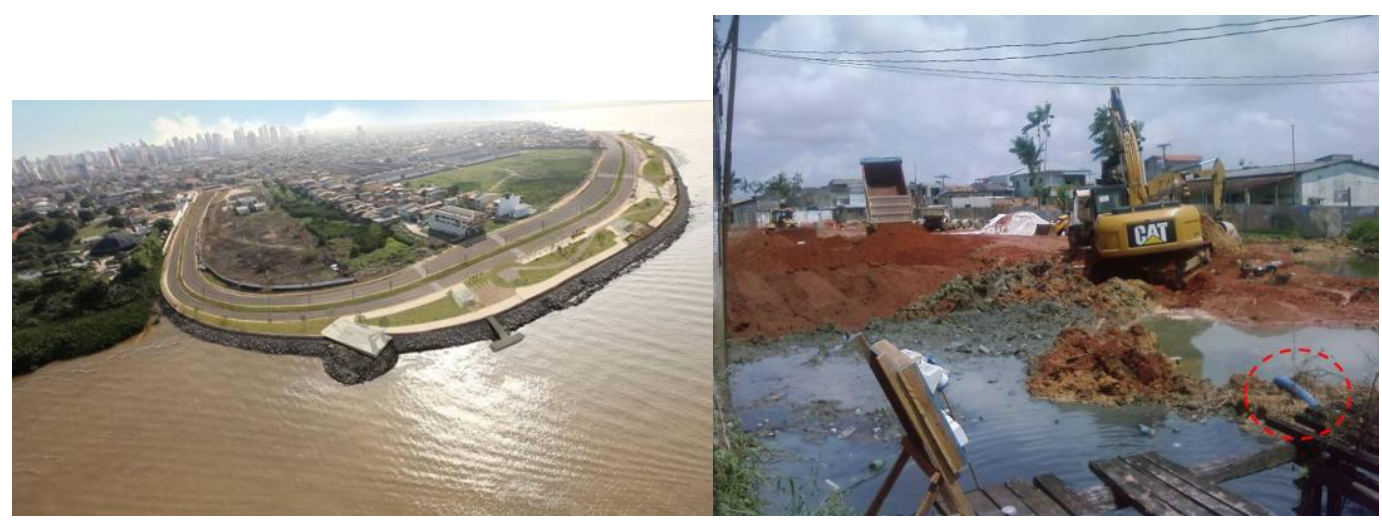

Figura 3. à esquerda retrata a "conclusão" da primeira fase do PROMABEN, a qual esta dividida em três fases, sendo denominada "Portal da Amazônia". Fonte: play47.blogspot.com e Figura 4. à direita aterramento e dragagem do canal Bernardo Sayão, com sucção das águas (círculo vermelho) para melhor aterrar e consolidar a área. Fonte: autor (novembro/2012).

Destaca-se segundo Araújo Júnior (2013) que as ações institucionais estão à frente de grande parte das transformações sofridas na paisagem urbana da cidade de Belém, em especial as ligadas à drenagem de áreas alagadas, dissecação de pântanos, dragagem, desobstrução e canalização de rios. Estas ações serão aqui denominadas de políticas públicas, entendidas segundo Peters (1986 apud SOUZA, 2006) como a soma das atividades dos governos que agem diretamente ou através de delegação e que influenciam a vida dos cidadãos.

Esta forma se enquadra no campo teórico do neo-institucionalismo, o qual enfatiza a importância das instituições/regras para a decisão, formulação e implantação de políticas públicas e que, no entanto, são mobilizados não só pelo autointeresse (decisões tomadas pelo mercado), mas também por processos institucionais de socialização, por novas ideias e por processos gerados pela história de cada país (SOUZA, 2006), beneficiando a coletividade, tornando-a parte dos processos decisórios.

Os problemas concernentes às áreas propícias a inundação e alagamentos sempre foram uma constante à cidade de Belém por esta ser amplamente recortada por cursos d'água. Ações institucionais através de Leis, Portarias e Resoluções, por certo, influenciaram diretamente a paisagem urbana de Belém do período imperial e republicano. Tais ações podem ser consideradas ações antrópicas que atuaram na 
gênese/modificação do modelado terrestre (relevo), induzindo o aparecimento de novas formas em consequência dos processos de alteração.

A partir da intensa ocupação dos bairros periféricos de Belém percebe-se ações institucionais e da sociedade civil, onde políticas públicas pontuais (retificação de canais, aterramentos de áreas alagadiças remanescentes, construção de pontes, asfaltamentos, etc) por parte do governo municipal, entram em desacordo com obras postas a cabo pela própria população, ou seja, obras que acontecem, muitas vezes, sem autorização ou fiscalização de profissionais capacitados para implementar infraestrutura adequada, visando sanar, mais que momentaneamente, problemas de caráter coletivo. Verifica-se, concordando com Souza (2006), que mesmo sanando impactos em curto prazo, a política pública é uma política de longo prazo e embora seja materializada através dos governos, não necessariamente se restringe a participantes formais, já que os informais são também importantes, logo, envolve vários atores e níveis de decisão.

Neste sentido o PROMABEN, tem por objetivo a promoção da qualidade de vida da população do Município de Belém através da recuperação socioambiental e da valorização do meio ambiente urbano (PMB, 2007a), com enfoque à área de influência (direta e indireta - mapa da figura 5) do programa situado na porção sul de Belém.

O Plano Diretor Urbano de Belém determina que a qualidade do espaço urbano deva ser avaliada pelos níveis de infraestrutura e serviços urbanos, presentes e ausentes, pelos níveis de conforto e qualidades ambiental, e estética. O Plano Diretor define também a faixa de domínio dos canais localizados em área urbana, dando especial destaque a BHEN.

A legislação incidente sobre o programa nos três níveis de governo (federal, estadual e municipal) diz respeito a temas ligados aos recursos hídricos, uso do solo e LA de intervenções que afetam a drenagem urbana, as quais permitem delimitar (figura 5) a área de influência direta (AID) e a área de influência indireta (AII). 


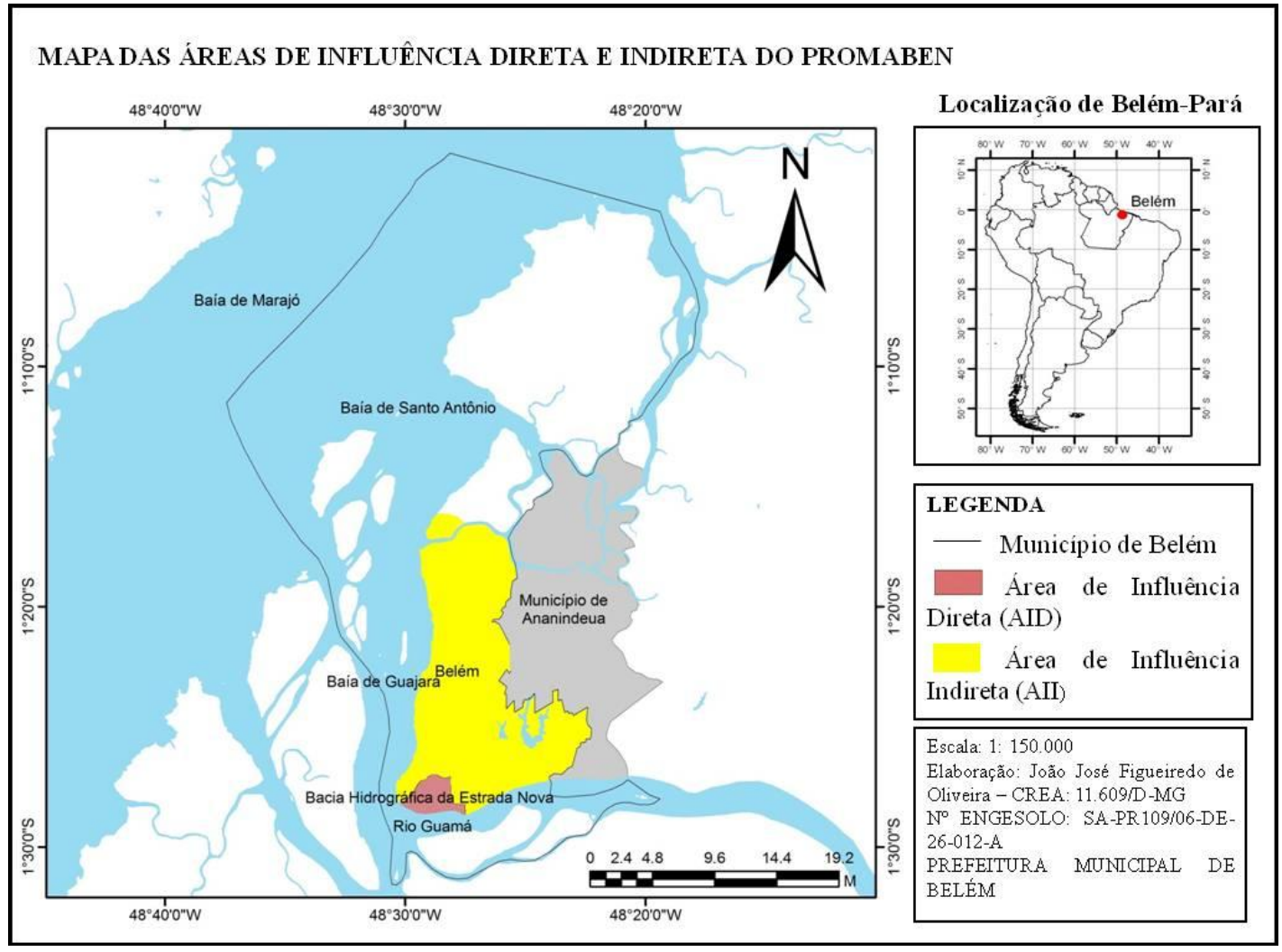

Figura 5. Mapa das áreas de influência direta e indireta PROMABEN. Fonte: adaptado de João José Figueiredo de Oliveira pelo autor.

A área de influência de um Programa como a que trata este estudo pode ser afetada direta ou indiretamente pelos impactos decorrentes de sua implantação e gestão. Essas áreas assumem tamanhos diferenciados, dependendo da variável considerada, quanto aos meios físico, biótico ou socioeconômico e a PMB (2007c) caracteriza-se a AID e a AII de acordo com o quadro 1.

\begin{tabular}{|c|c|c|c|}
\hline $\begin{array}{c}\text { Área de } \\
\text { influência do } \\
\text { PROMABEN }\end{array}$ & Abrangência & Critérios adotados para delimitação & Espaço físico \\
\hline AID & $\begin{array}{l}\text { Corresponde ao } \\
\text { espaço territorial } \\
\text { onde as relações } \\
\text { sociais, } \\
\text { econômicas } \\
\text { culturais, e as } \\
\text { características } \\
\text { físico-biológicas } \\
\text { sofrerão } \\
\text { impactos os } \\
\text { maneira primária, }\end{array}$ & $\begin{array}{l}\square \text { Definições de áreas onde haverá a } \\
\text { remoção de imóveis residenciais e de } \\
\text { desenvolvimento de atividades } \\
\text { econômicas, adotado para aplicação do } \\
\text { cadastro social e físico; } \\
\square \quad \text { As áreas correspondentes às } \\
\text { intervenções previstas pela adequação do } \\
\text { sistema de macro e microdrenagem, na } \\
\text { melhoria dos serviços de abastecimento de } \\
\text { água, esgotamento sanitário e coleta, } \\
\text { processamento e disposição final de }\end{array}$ & $\begin{array}{l}\text { Compreende os } \\
\text { bairros da Condor, } \\
\text { Jurunas, Guamá e } \\
\text { Cremação, e atinge } \\
\text { pequena parcela dos } \\
\text { bairros de Batista } \\
\text { Campos, São Brás, } \\
\text { Nazaré e Cidade } \\
\text { Velha. }\end{array}$ \\
\hline
\end{tabular}




\begin{tabular}{|c|c|c|c|}
\hline & $\begin{array}{l}\text { ou seja, há uma } \\
\text { relação direta de } \\
\text { causa e efeito, } \\
\text { compreendendo } \\
\text { ainda, uma } \\
\text { aproximação mais } \\
\text { detalhada das } \\
\text { áreas onde } \\
\text { ocorrerão as obras } \\
\text { físicas do } \\
\text { empreendimento. }\end{array}$ & $\begin{array}{l}\text { resíduos sólidos, e, referentes a } \\
\text { implantação de novas vias urbanas, } \\
\text { duplicação de vias existentes, instalação de } \\
\text { equipamentos urbanísticos e } \\
\text { remanejamento de população residente em } \\
\text { áreas de risco. } \\
\square \text { Os efeitos sinérgicos produzidos pelas } \\
\text { intervenções físicas e antrópicas, que } \\
\text { ocasionarão melhorias na qualidade } \\
\text { socioambiental da BHEN como um todo. }\end{array}$ & \\
\hline AII & $\begin{array}{l}\text { Corresponde ao } \\
\text { espaço territorial } \\
\text { aonde os impactos } \\
\text { se farão sentir de } \\
\text { maneira } \\
\text { secundária ou } \\
\text { indireta e com } \\
\text { menor intensidade. } \\
\text { Compreenderá o } \\
\text { território além da } \\
\text { AID, onde se } \\
\text { identificarão ainda } \\
\text { efeitos pela } \\
\text { extensão } \\
\text { multiplicação } \\
\text { indireta das ações } \\
\text { do Programa. }\end{array}$ & $\begin{array}{l}\square \text { Efeitos ao Planejamento e Operação do } \\
\text { Transporte Público Urbano - Alcance } \\
\text { efetivo dos efeitos das ações voltadas à } \\
\text { integração, melhoramento e criação de } \\
\text { vias de transporte nos bairros da AID que } \\
\text { permitirão maior incorporação das áreas } \\
\text { de baixadas da cidade à malha viária } \\
\text { urbana de Belém; } \\
\square \text { Efeitos ao Sistema de Destinação Final } \\
\text { dos Resíduos Sólidos de Belém - As ações } \\
\text { de saneamento básico, referentes a coleta } \\
\text { seletiva de lixo, implantação de Usinas de } \\
\text { Reciclagem e Compostagem no interior da } \\
\text { AID, diminuirão o volume atualmente } \\
\text { disposto no Aterro do Aura, que atende a } \\
\text { Belém como um todo, contribuindo para o } \\
\text { aumento de sua vida útil; } \\
\square \text { Efeitos ao Mercado Imobiliário de Belém } \\
\text { - é previsível uma valorização dos imóveis } \\
\text { na AID, que deverão integrar e dinamizar } \\
\text { o mercado imobiliário de Belém; } \\
\square \text { Limites Político-Administrativos das } \\
\text { ações para o meio Antrópico - Os efeitos } \\
\text { físicos e bióticos a serem causados na } \\
\text { Bacia da Estrada Nova, os quais } \\
\text { promoverão impactos nos índices de saúde } \\
\text { na AID, que se estenderão a toda } \\
\text { população de Belém continental. }\end{array}$ & 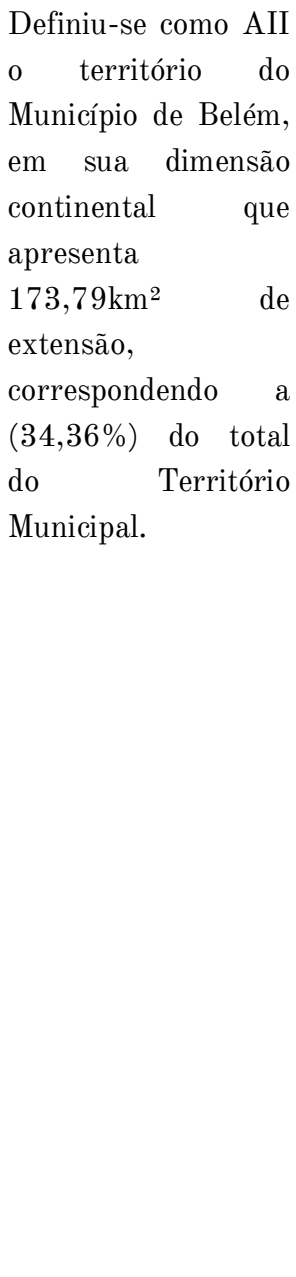 \\
\hline
\end{tabular}

Quadro 1. Área de influência direta e indireta do PROMABEN. Fonte: elaborado pelo autor com base em PMB (2007a).

Tem-se em vista que a PMB, buscando proporcionar melhorias na gestão público-administrativa nas áreas de domínio público municipal tem implantado programas e projetos de interesse coletivo, visando promover a cidadania com dignidade por meio da implantação de ações socioambientais na cidade. 
Para tanto, as ações elaboradas pelos diversos agentes que compõem a sociedade devem ser precedidas de um minucioso entendimento do ambiente e das leis que regem seu funcionamento (ROSS, 1990), bem como da relação natureza-sociedade procedida e em processo.

O contexto de intervenções institucionais e da sociedade civil em Belém mostra que as instituições são regras formais e informais que moldam o comportamento dos agentes. Assim, a teoria neoinstitucionalista favorece o entendimento de que não são só os indivíduos ou grupos que têm força relevante e influenciam as políticas públicas, mas também as regras formais e informais que regem as instituições.

O processo licitatório da obra PROMABEN traz consigo os cenários anteriores a obra, os quais, em resumo, não atendem as necessidades e anseios de uma população afetada por inúmeros problemas socioambientais. Tal processo vem também mostrar propostas de como poderá ser o futuro, ou seja, os cenários pós-obra a partir das medidas tomadas pela PMB, como na figura 6 .

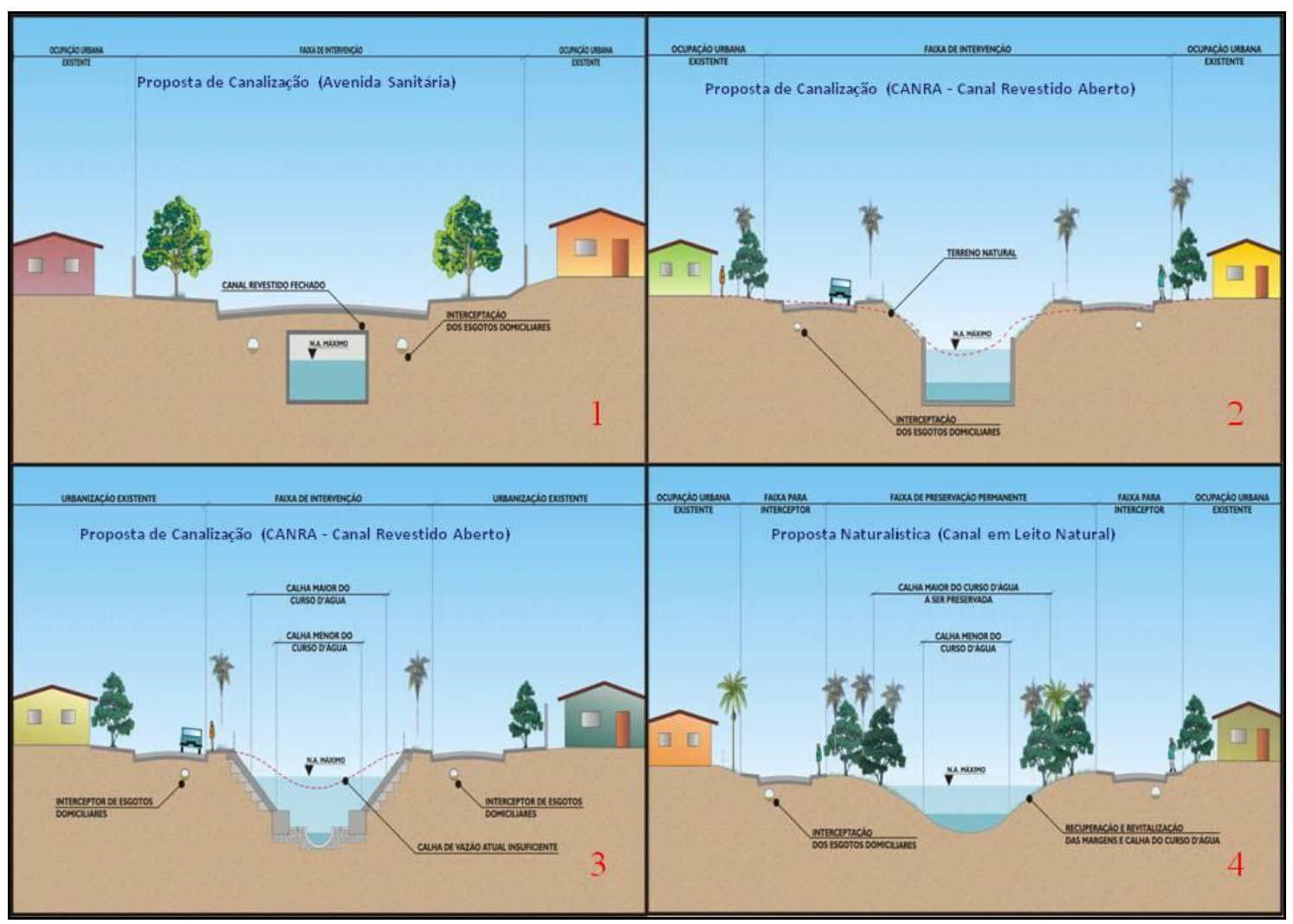

Figura 6. Propostas de intervenção para os cursos d'água componentes da BHEN. Fonte: PMB (2006) 
Para tanto, torna-se relevante levantar que as políticas públicas desenvolvidas e em desenvolvimento na cidade de Belém visaram e visam planejar o espaço urbano de forma a coadunar elementos políticos, econômicos, sociais, ambientais em âmbito integrado. No entanto, as intervenções alteraram a morfologia original da cidade em questão, gerando e intensificando processos, paradoxalmente, expondo as populações de espaços urbanos criados a riscos à inundação e alagamentos, tornando-as vulneráveis.

Com a obra em andamento verifica-se que a opção escolhida pela empresa que esta a frente da obra foi a proposta 1 (canalização - via sanitária) da figura 6, consistindo na implantação de galerias pluviais, cobertura e aterramento dos cursos d'água e consolidação da impermeabilização do solo na "planície de inundação", seja por concreto ou por asfalto (figuras 7 e 8).

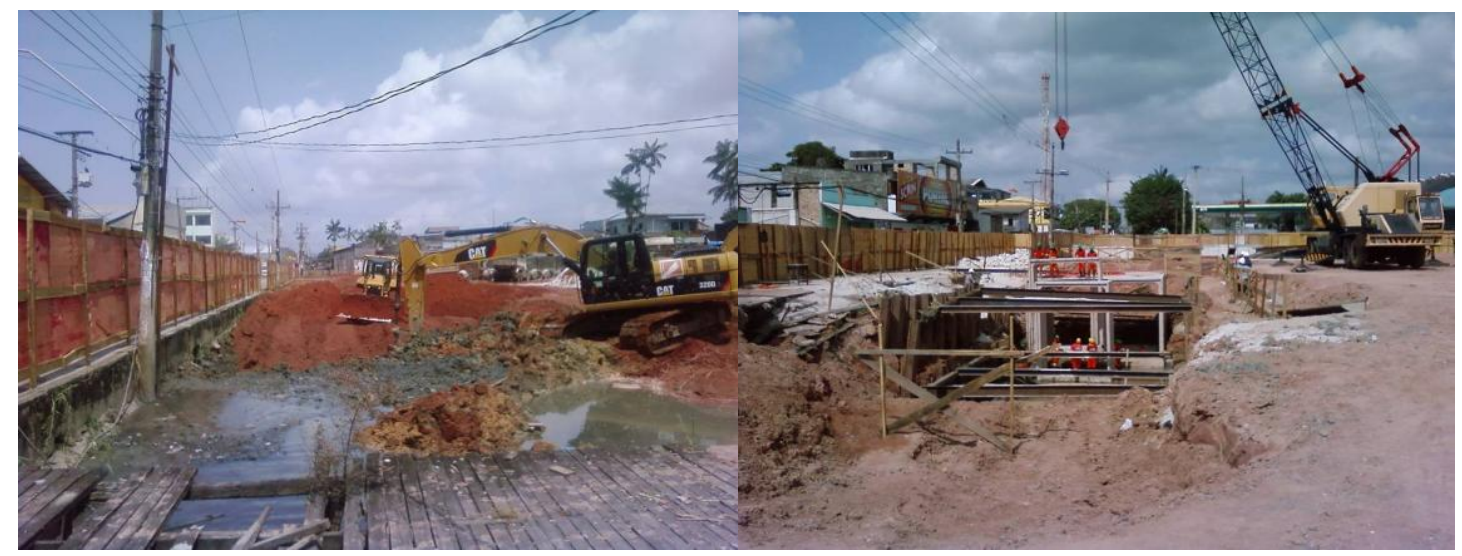

Figura \%. à esquerda canal da Bernardo Sayão sendo dragado, drenado e aterrado. Fonte: o autor (novembro/2012) e Figura 8. mostra a instalação das galerias pluviais em uma área da sub-bacia 4 no canal da Bernardo Sayão. Fonte: Adriane Azevedo (novembro/2012).

Com o LA do PROMABEN concedido a atuação da empresa responsável pela execução da obra vem se concentrando, principalmente, nas componentes de infraestrutura viária e sanitária (figura 9), com duplicação de vias e aterros. Para tanto, empreende o remanejamento de parte da população (figura 10) por meio de indenizações sobre a área construída, uma vez que por se tratar de terrenos de marinha não há título de posse. 


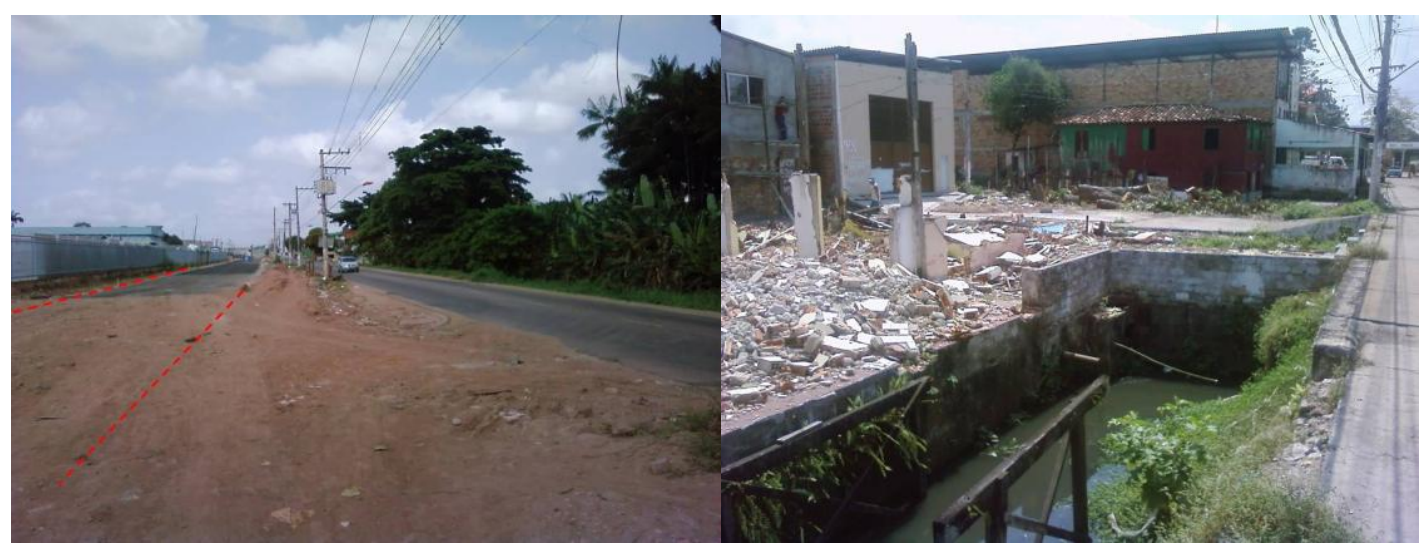

Figura 9. à esquerda tracejado esboçando a continuação da duplicação da Av. Bernardo Sayão. Fonte: o autor (novembro/2012) e Figura 10. tem-se o processo de demolição das residências localizadas as margens do canal da Bernardo Sayão. Fonte: o autor (novembro/2012).

Mesmo sabendo que os aspectos legais da obra "estão em dia" é preocupante saber que apesar de possuir um EIA e um RIMA bem estruturados, os quais contemplam as variáveis sociais, econômicas, políticas e ambientais é explicito que há um distanciamento entre a implantação que está ocorrendo e a implantação proposta.

Tal distanciamento é percebido devido praticamente não estar havendo participação efetiva da sociedade nos processos decisórios de transcurso da obra. É importante destacar que a população residente na área da BHEN é consultada e informada sobre o andamento das atividades postas em execução pela PMB e as empresas contratadas para dar continuidade a este empreendimento urbano.

Para tanto, é importante destacar que há uma gama de informações relacionadas ao PROMABEN em diversas secretarias municipais da cidade de Belém e este é um dos grandes complicadores no acesso a informação, a não sistematização das informações.

Um SIA eficiente poderia congregar as informações ambientais da BHEN em um sistema digital na internet para acesso ao público, mas somente isso não é suficiente, visto que a maior parte da população residente na área da BHEN reside em domicílios com baixo padrão de renda per capita figura 11, sendo importante para tal a instalação de uma base física com computadores e de 
preferência pessoas ligadas ao PROMABEN para auxiliar no acesso a informação e prestar possíveis esclarecimentos.

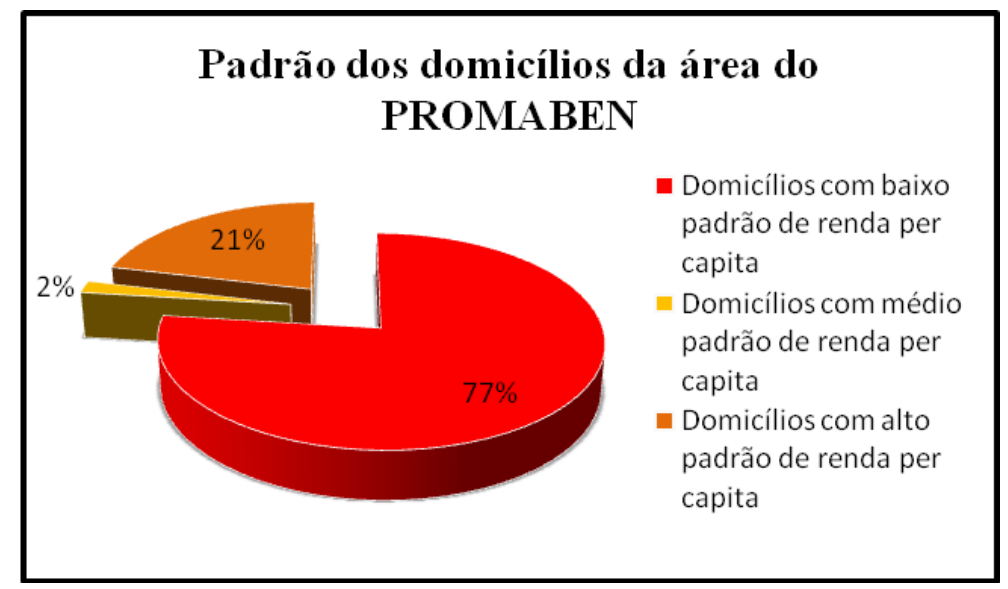

Figura 11. Padrão dos domicílios considerando a renda per capita. Fonte: elaborado a partir de IBGE (2010)

Um LA mais coerente com os interesses da população residente na área da BHEN deveria primar pelo esclarecimento e transparência no fornecimento de informações ambientais, uma vez que tais informações lhes são uteis para atuar de forma mais incisiva nos processos decisórios de transformação e adequação deste espaço geográfico.

\section{CONSIDERAÇÕES FINAIS}

A constituição de um Sistema de Informação Ambiental (SIA) é uma importante ferramenta para subsidiar a implantação mais eficaz de Licenciamentos Ambientais (LAs) de caráter mais participativos. Mesmo sabendo que o LA tem caráter legal, a participação da população seria salutar, pois validaria bem mais as ações futuras a serem implantadas.

Não se pode perder a dimensão que não somente aspectos técnicos (computadores - softwares e hardwares) são importantes em um SIA, mas os aspectos humanos são imprescindíveis para discernir com clareza as reais condições vividas e experenciadas pela população. 
Considerar os aspectos humanos como anteriores aos aspectos técnicos perpassa por ter clareza de que a sociedade como impactada (positiva ou negativamente) por processos de intervenção ambiental (rodovias, barragens, diques, contruções em áreas de risco, etc) deve ter de antemão a informação necessária para atuar não só de direito, mas de fato, posto que este é um direito assegurado pela lei, mas muitas vezes negado, seja por instituições públicas ou privadas.

Por fim, considera-se que um sujeito ambientamente formado é aquele que antes de mais nada tem acesso a informação e é capaz de discernir entre o certo e o errado, sendo capaz ainda de, no sentido marxista, pensar seus atos filosoficamente, em uma práxis realmente transformadora.

\section{REFERÊNCIAS}

ARAÚJO JÚNIOR, A. C. R. Planejamento urbano-ambiental na cidade de Belém (PA): reflexões sobre o PROMABEN. Desenvolvimento e Meio Ambiente, v. 27, p. 179-192, jan./jun. 2013.

BARROS, L. V.; PAIVA, R. Sistematização de informações sobre desmatamento da Amazônia: uma análise sob a ótica do direito à informação, a partir de critério de acessibilidade. DataGramaZero - Revista de Ciência da Informação - v.11 n.4 ago/2010.

BRASIL. Lei $n^{\circ} 10.650$ de 16 de abril de 2003. Dispõe sobre o acesso público aos dados e informações existentes nos órgãos e entidades integrantes do Sisnama. Diário Oficial da República Federativa do Brasil, Brasília, DF, 16 abr. 2003.

Lei $n^{0}$. 6.938 de 31 de agosto de 1981. Dispõe sobre a Política Nacional do Meio Ambiente, seus fins e mecanismos de formulação e aplicação, e dá outras providências. Oficial da República Federativa do Brasil, Brasília, DF, 31 ago. 1981.

CARIBÉ, R. de C. do V. Subsídios para um sistema de informação ambiental no Brasil. Ciência da Informação, Brasília, v. 21, n. 1, p. 40-45, jan./abr. 1992.

Conselho Nacional de Meio Ambiente (CONAMA). Resolução no 237, de 19 de dezembro DE 1997

INSTITUTO BRASILEIRO DE GEOGRAFIA E ESTATÍSTICA (IBGE). Censos demográficos 1950, 1980, 1991, 2000 e 2010. Disponíveis em: www.ibge.gov.br.

INSTITUTO DO DESENVOLVIMENTO ECONÔMICO E SOCIAL DO PARÁ (IDESP). Belém: estudo ambiental do Estuário Guajarino. Belém: Idesp. Relatórios de Pesquisa nº 17, 1990.

PERSEgona, M. F. M. Proposta para aperfeiçoamento do Sistema de Informações Ambientais do Sistema Nacional de Meio Ambiente. Disponível em: <http://facsenac.edu.br/portal>. Acesso em: 16 dez. 2013.

PMB - PREFEITURA MUNICPAL DE BELÉM. Programa de Recuperação Urbana e Ambiental da Bacia Estrada Nova. Relatório de Impacto Ambiental. Tomo 01/02: Engesolo Engenharia LTDA, 2007a.

. Disponível em: <http://www.belem.pa.gov.br>. Acesso em: 2007b. 
. Programa de Recuperação Urbana e Ambiental da Bacia Estrada Nova. Estudo de Impacto Ambiental. Tomo 02/03: Engesolo Engenharia LTDA, 2007c.

Portal da Amazônia: Urbanização da bacia da Estrada Nova e Orla do rio Guamá. Audiência UFPA. PMB/SEURB, 2006.

ROSS, J. L. S. Geomorfologia: ambiente e planejamento. São Paulo: Contexto, 1990.

TAVARES, C.; FREIRE, I. M. Informação ambiental no Brasil: para quê e para quem. Perspectivas em Ciência da Informação, Belo Horizonte, v. 8, n. 2, p. 208-215, jul./dez. 2003. 